\title{
A Tradição Histórica da Aprendizagem Industrial
}

JoAquim Faria Góes Filho

\section{A APRENDIZAGEM ASSEGURADA PELO EMPREGADOR NA FASE DE PEQUENA OFICINA}

A

história da formação do obreiro para o artesanato constitui por certo um dos capítulos dignos de maior atenção no estudo da tradição histórica da aprendizagem.

Com a expansão do comércio no século XII, surgem os burgos e as cidades comerciais. Nesses centros localizam-se artesãos com o objetivo de produção de objetos de uso e de adôrno para a venda. Quando o número de homens que trabalhavam num mesmo ofício se torna considerável, começa a surgir a tendencia a se unirem entre si. Dai as guildas especiais de artífices.

Estamos em pleno periodo do trabalho puramente manual. Não há máquinas e são usadas ferramentas dos tempos mais antigos. A indústria é puramente doméstica e sua capacidade de produzir, limitada. Mas não é só. Entre os direitos das guildas, o de estabelecer o privilégio do ofício é dos mais importantes. Só os membros da corporação podiam exercer a profissão e só havia um caminho para o ingresso na mesma: o do aprendizado.

Este fazia-se, em regra, na casa do próprio mestre, que era a um tempo a sua residência e oficina. Na sala dos fundos trabalhavam o mestre, os companheiros e os aprendizes, nos objetos que eram vendidos pela espôsa e pelas filhas, na sala da frente.

Segundo Kauser (Ouvriers du temps passé), e outros autores citados por Adrian ANTHERo, era a seguinte a situação dos companheiros e dos aprendizes:

"Os aprendizes não exerciam nenhum direito. Gozavam apenas da proteção juranda; e, a não serem filhos de mestres, pagavam pela aprendizagem um tanto à corporação, e, em algumas cidades reais, também um tanto ao próprio rei. Não podiam abandonar os mestres e trabalhavam para êles. Em troca, eram alojados, vestidos e alimentados. Os obreiros (companheiros), cujo número era indeterminado, gozavam já de certos direitos. Só eram admitidos como tais, depois de terem feito alguma obra 
especial e de valor. Seu trabalho era remunerado. Não podiam abandonar os mestres, mas, também, não podiam ser despedidos sem razão. Os mestres gozavam de muitos privilégios. Era reduzido o seu número e, para ser preenchida a vaga dos que faleciam, requeriam-se muitas formalidades, além de o eleito dever pagar um tributo à corporação e, muitas vêzes ao próprio rei. Uma dessas formalidades consistia no concurso, em que o candidato se mostrava habilitado a exercer o cargo, sendo que os outros mestres, depois de jurados, isto é, depois de ajuramentados, é que presidiam à referida prova. Do fato de os examinadores terem de ser jurados, ou ajuramentados, foi que proveio a denominação de "jurandas".

Outro aspecto digno de ser assinalado é que o mestre mantinha em sua casa e oficina poucos aprendizes. Uma das razões disso residia na necessidade de ensinar bem aos aprendizes. A produção era em pequena escala. Atribuía-se grande importância à qualidade do produto, a seu acabamento, a seu refinamento. O trabalho assentado nessa base determinava que se insistisse em certas qualidades morais do produtor. A guilda interessada em manter o standard da produção exercia ação fiscalizadora sôbre a aprendizagem, bem como sôbre oficiais e mestres e ainda sôbre os trabalhos que iam ser postos à venda. Grande zêlo por parte das guildas era posto na verificação dos metais preciosos. Nos tecidos foi proibido, durante muito tempo, a mistura de fios de lá, linho e sêda. Não era permitido o uso de vidros de côr em lugar de pedras preciosas, ou a ornamentação de peças de osso com ouro ou prata, de modo a permitir que pudessem ser vendidas como sendo de marfim. A formação moral do aprendiz, que havia de ter, no futuro, uma grande integridade no trabalho, fazia-se desde cedo na oficina, no ambiente da familia do mestre. A educação religiosa e cívica fazia-se no contato com a igreja e com as autoridades da corporação. A educação variava muito, de acôrdo com os conhecimientos dos mestres, incluindo, por vêzes, a leitura, a escrita e o cálculo. O ensino da parte técnica era longo, por isso que se impunha o aprimoramento do produto, como dissemos acima. Algumas vêzes durava até sete anos, como se vê nos "Estatutos dos aprendizes na Inglaterra". Métodos empíricos tornavam a aprendizagem muito lenta e estereotipada. A promoção aos postos ulteriores da carreira, isto é, à situação de companheiro e de mestre, reclamava provas de grande adestramento e habilidade, como já dissemos anteriormente. Para a última etapa, pedia-se do candidato a realização de uma obra-prima em seu oficio. Na guilda dos sapateiros de Paris exigia-se que o futuro mestre, por exemplo, fizesse um par de botinas, três pares de sapatos, um par de chinelos, devendo tudo ser realizado com o melhor acabamento. Outro fator a determinar a redução do nú- 
mero de aprendizes era a necessidade de limitar o número de concorrentes na profissão.

Com o correr dos tempos, algumas modificações de relêvo se fizeram sentir no regime da aprendizagem. Com o aumento do consumo e o maior reclamo de produção, o mestre foi levado a elevar o número dos obreiros. Sendo muitos a trabalhar em uma mesma sala, já não era possivel ao mestre ensinar individualmente a cada um dos aprendizes. Cada um dos obreiros passa então a dirigir de cinco a dez menores. E, à medida que se amplia a divisão do trabalho, há menos tempo para ministração de ensino.

Os aprendizes passam a ser absorvidos nos trabalhos que dão mais lucros à oficina. As relações de pai para filho existentes entre mestre e aprendiz são substituidas pelas de empregador e empregado.

\section{A APRENDIZAGEM MINISTRADA PELO EMPREGADOR NA FASE DO TRABALHO EM FÁBRICA}

A introdução do uso da máquina elementar, além do uso de ferramentas manuais, caracteriza a segunda etapa.

Desde 1705 que Newcomen inventara a caldeira utilizada no esgotamento das minas, obtido pela fôrça do vácuo debaixo do piston; para isso introduzia-se ali vapor d'água, que era condensado com um jato de água fria. Entretanto, a caldeira de NewComen náo possuía manivela nem produzia movimento rotativo. PAPIN e Thomaz SAVEry empregaram também o vapor. Foi, entretanto, JAMES WATT, um construtor de instrumentos da Universidade de Glasgow, quem juntou ao novo engenho uma manivela e uma roda $e$, finalmente, um conjunto de válvulas mecânicamente adaptadas para a introdução do vapor. Grandes dificuldades surgiram na construção dessa nova máquina, pois a fundição era muito imperfeita e pouco se sabia a respeito da resistência do material para suportar a pressão e o trabalho constante com determinada velocidade. A lubrificação constituia outro problema a ser resolvido. WatT e Foulton trouxeram, também, ponderável contribuição à substituição da fôrça da água pela do vapor. A caldeira tornou-se imperativa onde era indispensável fôrça geradora artificial. Sua primeira aplicação em uma fábrica de tecidos foi feita em Papplewich, em 1785. Quando o carvão e o ferro estavam no mesmo lugar, como acontecia no norte e centro da Inglaterra, a máquina de WATT era logo acolhida. Até o aparecimento da turbina a vapor, um século mais tarde, a máquina a vapor melhora as condições da produção, mas não altera substancialmente os principios em que esta se estabelecera, baseada no uso da fôrça humana, do vento, do cavalo, do boi e da água. 
$\mathrm{E}^{\prime}$ que o progresso da máquina estava ligado ao da produção do ferro e do aço. Os mecanismos tinham que ser feitos dos materiais de certa qualidade, tamanho e forma. A fusão dos metais em determinados tamanhos, qualidade e precisão só então começa a tornar-se possivel. Em 1735, abriram-se novas perspectivas, quando o ferro foi, pela primeira vez, fundido com o coque. A exploração das minas, como a fundição de grandes peças de ferro para máquinas, demandava, por outro lado, uma grande organização e inversão de capitais vultosos. Muitos problemas de natureza técnica, relativos à exploração do ferro e à fabricação do aço, só muito mais tarde, com o desenvolvimento da química, puderam ter solução.

Em 1733, JoHN KAY tira patente da inovação que fizera na roda de fiar, à qual êle ajuntara um número de lançadeiras volantes, reduzindo à metade o trabalho requerido para tecer. Cêrca de 1767. James Hargreaves construiu uma máquina que consistia, na prática, em uma roda com muitos fusos, oito, a princípio, e oitenta, quando êle morreu. No comêço a máquina era leve, mas, à medida que aumentava de tamanho, surgia o problema da fôrça necessária para impulsioná-la. A primeira máquina de fiar de feição prática foi chamada de "estrutura d'água", porque reclamava o uso da fôrça da água. Richard ARKwIGHT introduziu nela alterações em 1769. Sua primeira máquina foi movida por fôrça de cavalo até 1771 , quando foi usada a fôrça da água. Em 1779, Samuel Grompton introduziu novos aperfeicoamentos, que tornaram possivel produzir qualidades mais finas de pano, para competir com as Indias Orientais. Em 1792, Eli WhitNey (americano) construiu, com sucesso, o primeiro descaroçador de algodão. Esta máquina acarretou uma revolução em tôda a indústria, tornando possivel a produção em grande quantidade da fibra pronta para fiar e por baixo preço. Numerosos outros aperfeiçoamentos ainda foram introduzidos na máquina de tear por RADELIFF, HoRROCKS e outros. O tear mecânico para fazer panos mais finos teve que esperar até que a metalurgia e as máquinas de precisão, em geral, tivessem atingido um estágio mais alto de desenvolvimento. Os modêlos Kenworthy e BuLLOUGH, aparecidos em 1841. marcam a transição para o atual sistema.

Nessa fase perduram as oficinas domésticas, mas multiplicam-se as fábricas. Entre os muitos efeitos resultantes de sua expansão, nota-se a alteração das formas do trabalho, sobretudo no que se refere à substituição dos processos de trabalho manual do artifice por outros feitos por mecanismos.

A produção é dividida em tarefas. A cada trabalhador, ou a cada conjunto dêstes, cabe uma dessas tarefas. O operário não 
se ocupa em fazer ou ajudar a fazer um objeto, com o mestre ou com o companheiro, como acontecia antes.

Êste fracionamento impõe uma direção, um contrôle, que é exercido por um homem à frente da fábrica, e freqüentemente, por êste e por vários prepostos que comandam setores. Generaliza-se, assim, em vários paises, a prática da divisão do trabalho.

A competição se torna aguda. A procura do trabalhador barato acentua-se de tal modo que as crianças pobres são negociadas com proprietários das fábricas e aos mesmos enviadas em verdadeiros rebanhos. No campo, são alojadas no próprio recinto da fábrica ou em alpendres especialmente construidos para êsse fim, continuamente ocupados pelas turmas de menores que se alternam dia e noite no trabalho.

A alimentação era limitada e o grau de mortalidade elevado. Em 1796 "o Board de Saúde" de Mancherster, investigando as causas do espraiamento de moléstias contagiosas, aponta os aspectos monstruosos dêsse tipo de trabalho da criança como o principal responsável. E uma grande agitação contra o tratamento desumano dado a menores inicia-se na Inglaterra. Surge então a intervenção do Estado, protetora do menor. Em 1802, o primeiro ato legislativo sôbre fábricas é votado pelo Parlamento (The Factory Act). Esta lei estabelecia o limite de doze horas de trabalho diário para menores e o proibia além de nove da noite. Exigia, além disso, que fôsse dado ao aprendiz trabalhador o ensino da leitura, da escrita e do cálculo, bem como determinava a existência de certas condições sanitárias. Este ato teve a oposição dos proprietários de fábricas, que desejavam o trabalho das crianças sem restrições e, em 1814, a lei foi revogada. Em 1830 , LORD Ashley bateu-se por uma lei que limitasse a dez horas o trabalho dos menores, mas é derrotado. Southey, o poeta, escreveu a respeito das condições de vida nas fábricas: "eu não creio que haja nada mais desumano e que mais tenha desgraçado a natureza humana em qualquer tempo ou pais". Em 1833, outra lei foi votada, estabelecendo que a educação e o trabalho deviam ser combinados. Em 1844, nova lei foi decretada, prevendo a redução de horas de trabalho e estabelecendo obrigações para os pais em relação à educação geral dos menores.

\section{A APRENDIZAGEM MINISTRADA PELO EMPREGADOR NA FASE DO GRANDE DESENVOLVIMENTO INDUSTRIAL, EM \\ NOSSOS DIAS}

$\mathrm{Na}$ segunda parte da revolução industrial, assistimos a uma maior divisão das operações, cada uma delas feita por uma máquina especial, em geral automática. Uma tremenda competição de mercados impulsiona as indústrias e um dos instrumentos para a 
conquista dêsses mercados é a possibilidade de vender mais barato. Produzir muito, através da máquina, significa abaixar o custo da unidade produzida. A "mass production" passa a constituir a base comercialmente sã da operação das fábricas. A estandardização e a produção em série são duas parcelas do processo da "mass production". Fixado um padrão, não resta senão executá-lo, sempre igual, na maior quantidade possivel. Eliminam-se, assim, novos esforços, dispersão de energias, perda de tempo, o que vale dizer despesas.

Tôda essa experiência a que o homem chega com a maquinaria que já possui leva o à verificação de que, quanto maior fôr a redução das operações manuais custosas, mais se apressa a produção e mais se reduz seu custo. Novas máquinas automáticas, ainda mais complicadas que as precedentes, são, então, inventadas, para fazer algumas ou muitas das operações manuais ainda subsistentes. O resultado é uma extrema divisão do trabalho e uma especialização máxima de cada trabalhador. A máquina faz tudo ou quase tudo. $O$ operário passa a ser um simples manipulador de chaves e alavancas ou condutor de matériaprima. Em alguns casos, cabe-lhe ainda executar algumas operações de natureza técnica, mas tão reduzidas e tão iguais, que podem ser aprendidas em meses ou semanas. Uma parte dêsse operariado se inclui no grupo dos semiqualificados. Mas a imensa maioria dos "manipuladores" é composta de pessoal a que nâo se pede nenhuma qualificação técnica especial. Essa a nova população que aflui para o trabalho em fábrica, com a grande indústria, constituindo a maior percentagem dos obreiros da nossa era.

$\mathrm{E}^{\prime}$ evidente que há fábricas que oferecem outro panorama. As indústrias chamadas "de qualidade" $e$ as que fabricam máqui nas para as demais são dois exemplos de tipos que apresentam maior percentagem de operários qualificados è semiqualificados, do que obreiros do último grupo. Mas constituem minoria.

Essa profunda modificação industrial alterou grandemente os processos e métodos da aprendizagem das ocupações no próprio emprêgo, mas não a eliminou. Ao contrário, o que se deu foi um aumento enorme do número de jovens em fase de treinamento inicial, por isso que a mecanização fabril não determinou redução de mão-de-obra nas fábricas, mas deslocamentos de massass de obreiros de ocupações mais dificeis e exigentes do ponto-de-vista da perícia individual para atividades extremamente simples, iguais e repetidas.

A necessidade do treino de milhares de jovens que todos os dias buscam emprêgo em fábricas passou a ser extremamente importante, em face à complexidade mecânica do equipamento e dos processos de produção, à entrosagem de cada indivíduo em 
conjuntos de milhares de homens, todos agindo sincrônicamente, ao alto custo dos equipamentos e da matéria-prima que vão ser manejados pelo novo operário, aos aspectos qualitativo e quantitativo da produção, cujos índices devem ser atingidos, aos problemas de segurança no trabalho, à disciplina, aos hábitos de obediência a chefes e a instruções fundamentais, ao senso de responsabilidade, a regras de convivência com uma população obreira no mesmo local etc.

$\mathrm{O}$ conceito moderno de aprendiz vem ganhando contornos nos quais se busca manter a continuidade de um sistema que se revelou capaz de assegurar a renovação e a expansão dos quadros de trabalhadores da indústria moderna.

Em primeiro lugar, há que anotar-se a proteção que as convenções $e$ as leis modernas procuram assegurar ao menor no instituto da aprendizagem. Patrão e aprendiz firmam um contrato em que os objetivos dominantes são os atos de ensinar e de aprender, que se constituem em obrigações reciprocas, sob a vigilância e a proteção do Estado.

As citações seguintes fixam uma linha conceitual constante:

Estados Unidos - "Aprendiz é uma pessoa de, pelo menos, 16 anos de idade, protegido por um acôrdo registrado num Conselho Estadual de Aprendizagem, que lhe garanta um minimo de 4.000 horas de emprêgo razoàvelmente continuo e sua participação num regime aprovado de experiência de trabalho, o qual deve ser suplementado por 144 horas, por ano, de aulas de matérias correlatas".

Nova Zelândia - "A palavra aprendiz aplica-se a pessoas de ambos os sexos contratadas para servirem a um empregador. e para aprenderem qualquer ofício na indústria".

Vitória - "Aprendiz é qualquer pessoa que, de conformidade com esta lei, está ligada, por contrato ou transferência de contrato, a um empregador, para aprender um oficio de aprendiz".

"Ofício de aprendiz" significa um oficio qualificado, proclamado por esta Lei como tal".

Queensland - "Aprendiz é qualquer pessoa contratada com a finalidade de ser instruida no conhecimento e na prática de qualquer ofício".

Dominio do Canadá - (Contrato de Aprendiz) - "Aprendiz é uma pessoa de, pelo menos, 16 anos de idade, que faz um contrato por escrito com um empregador, a fim de aprender um ofício qualificado, requerendo um mínimo de 4.000 horas de emprêgo razoàvelmente contínuo, devendo participar de um programa de experiência prática e de instrução técnica adequada a tal pessoa". 
Nova Escócia, Alberta e Ilha Principe Eduardo - " Aprendiz é uma pessoa de 16 anos, no minimo, que faz um contrato de serviço de acôrdo com esta lei, pelo qual receberá do seu empregador, ou por intermédio dêle, total ou parcialmente, treinamento e instrução em qualquer ofício designado".

Grã-Bretanha - "Aprendizagem é a relação contratual entre o empregador e o operário, pela qual o empregador é obrigado a ensinar ao operário ou proporcionar os meios para que êste aprenda qualquer ofício ou ocupação e, em consideração a essa aprendizagem, o operário servirá ao empregador, como aprendiz, durante um periodo determinado e especificado. Poderá ser um acôrdo verbal ou escrito".

New Brunswick - "Aprendiz é uma pessoa de, pelo menos, 16 anos de idade, que faz um contrato de aprendizagem com um empregador, de acôrdo com o estabelecido nesta lei".

Ontário - "Aprendiz é uma pessoa de, pelo menos, 16 anos de idade que faz um contrato de serviço, pelo qual receberá do seu empregador ou por intermédio dêle, total ou parcialmente, instrução para um ofício designado".

Manitoba e Saskatchewan - "O mesmo que para o Contrato do Dominio do Canadá".

Columbia - Bretanha - "Aprendiz significa uma pessoa de 15 anos de idade, pelo menos, que faz um contrato de serviço de acôrdo com esta lei e que, pelo menos, receberá do seu empregador, ou através dêle, instrução para um ofício designado".

("Apprenticeship in Canada. Department of Labour").

França - "No contrato de aprendizagem, o chefe de uma firma industrial ou comercial, um artesão ou um operário qualificado, obriga-se a dar ou a proporcionar um treinamento profissional prático e completo a outra pessoa, a qual, por sua vez, compromete-se a trabalhar para o primeiro sob várias condições e durante um período de tempo determinado". (French Law Pertaining to Apprenticeschip) - Legal nature of Apprenticeship and rights and liabilities of apprentices under the french code of labor and social welfare. (Code du travail et de la prévoyance sociale, XIX Edition, 1954) - (Vocational Education - Bulletin $\mathrm{n}^{\circ} 176$ - Apprendticeship in England, France and Germany).

Alemanha - "O alicerce da indústria alemã é o seu estoque de mecânicos e de operários qualificados perfeitamente treinados. O fato de a Alemanha ser tão bem suprida de bons operários e artesãos resulta, tão sòmente, pode-se dizer, do sistema de aprendizagem. A aprendizagem, na Alemanha, é uma continuação do velho sistema instituido pelas ligas artesanais (hand-craft) na 
Idade Média". (Vocational Education - Bulletin n² 176 - Apprenticeship in England, France and Germany).

"A lei moderna relativa à aprendizagem é, antes de tudo, um resultado de decisões judiciais. Existem, porém, certas obrigações estatutárias que devem ser observadas, principalmente por ser a relação entre o aprendiz e o seu mestre uma relação de contrato. Todo acôrdo de aprendizagem deve incluir um compromisso, da parte do mestre, de ensinar, caso contrário não será um acôrdo de aprendizagem". (Apprenticeship for a skilled trade - By F. Twyman).

"O segundo elemento comum encontrado nas definições sugeridas estabelece que a aprendizagem comporta uma troca de compromissos entre o mestre e o aprendiz; o primeiro obrigando-se a empregar o segundo e a ensinar-lhe, ou fazer-lhe ensinar um ofício no seu estabelecimento, enquanto o segundo compromete-se, durante o tempo da aprendizagem, a trabalhar e a aprender o referido ofício". (Conférence Internationale du Travail - VingtCinquième Session - Genève, 1939 - Enseignement Technique et Professionel et Apprentissage).

"Esste capitulo não tem a pretensão de formular uma definição "internacional" de aprendizagem, recomendada a todos os países para adoção e destinada a substituir as definições mais concretas que possam conter, a êste respeito, as legislações nacionais ou os convênios coletivos. Seu único objetivo é precisar o sentido em que foi utilizada a expressão na recomendação que propomos.

Para isto, procurou-se fazer uma sintese dos principais elementos constitutivos da noção de aprendizagem, tal como resultam das respostas dadas pelos governos.

Estes elementos constituem a relação contratual que deve existir entre o mestre de aprendizagem e o aprendiz; os compromissos reciprocos que levam consigo, por parte do primeiro, a obrigação de ensinar ou de fazer ensinar um ofício, e, por parte do segundo, a obrigação de aprender êsse ofício executar seu trabalho para o empregador; e, finalmente, as condições inerentes à forma sistemática que deve revestir esta preparação e sua duração, a qual deve ser fixada prèviamente". (Conferencia Internacional Del Trabajo - Vigésima Quinta Reunión - Genebra, 1939 - Enseñanza Técnica y Profesional y Aprendizaje).

"De acôrdo com a finalidade da presente Recomendação, o têrmo "aprendizagem" aplica-se a todo sistema em virtude do qual o empregador se obriga, mediante contrato, a empregar um jovem trabalhador e a ensinar-lhe, ou fazer-lhe ensinar, metòdicamente, um ofício, durante um periodo prèviamente fixado, e du- 
rante o qual o aprendiz trabalhará a serviço do dito empregador". (Conferencia Internacional del Trabajo - Recomendación (num 60) Relativa al Aprendizaje).

\section{A TRADIÇÃO BRASILEIRA DA APRENDIZAGEM ASSEGURADA PELO PRÓPRIO EMPREGADOR}

Eis um setor em que podemos afirmar a existência de velha tradição no Brasil, sobretudo se considerarmos as atividades artesanais.

Os primeiros artífices que tivemos no período colonial vieram da Metrópole. Carpinteiros, marceneiros, sapateiros, alfaiates, oleiros, ceramistas, pedreiros, estucadores, ferreiros, tipógrafos, santeiros, escultores, ourives e joalheiros de lá nos foram enviados e aqui, nas suas tendas, ensinaram a aprendizes menores os segredos dos seus ofícios, à medida que iam atendendo às suas encomendas. Dos aprendizes surgiram oficiais e, dêstes, novos mestres, tal como ocorria na Europa renascentista.

Tal sistema de aprendizagem no artesanato vem até a Independência e até a República sem nenhuma modificação, a não ser a do surgimento de novos ofícios com a instalação no Pais de novos imigrantes, não só portuguêses, como espanhóis, italianos, alemães, poloneses, sírios etc.

A tradição da aprendizagem de menores e adultos em fábricas é também antiga, tão antiga quanto o aparecimento de indústrias no País. Uma das primeiras em nosso meio é a indústria têxtil, que sempre empregou, além de operários adultos do sexo masculino, grande número de menores e mulheres.

Durante mais de cinqüenta anos, a maquinaria têxtil foi importada da Inglaterra e, para montá-la, vinham técnicos e mes. tres inglêses, que aqui permaneciam nas funções-chave da produção e no treino de operários brasileiros no manejo dos fila tórios e dos teares.

Outras indústrias de bens de consume que se foram fixando no Pais trilharam caminho semelhante.

A expansão da indústria brasileira durante as duas grandes guerras e seu interregno nos fêz atingir a cifra de cêrca de um milhão de operários.

Salvo a parte preenchida por artífices e técnicos europeus que emigraram para o Brasil e a reduzida oriunda de escolas profissionais do govêrno, essa massa de operários aprendeu as tarefas no próprio emprêgo, durante periodos menores ou maiores de treinamento. Êste já não podia seguir as formas da velha aprendizagem do artesanato, mas não obedecia a sistemas ou 
métodos organizados. O nôvo empregado aprendia as tarefas vendo um operário já feito executá-la e tentando imitá-lo.

Pode-se afirmar que o Estado permaneceu indiferente a êsse processo de formação de mão-de-obra no próprio trabalho. As suas preocupações se dirigiam antes ao preparo de operários em escolas profissionais oficiais ou a estas equiparadas, fora do am biente fabril.

A partir de 1930, o Estado começa a intervir no trabalho de menores nas fábricas, estabeleecndo o limite de 14 anos para a sua admissão, proibindo o trabalho noturno e em ocupações e ambientes prejudiciais à sua saúde.

Nessa legislação percebeu-se a influência dos principios debatidos no "Bureau International du Travail", de Genebra, representativos do curso da opinião mundial na matéria. Essa mesma influência nos conduziu mais tarde a um passo extremamente importante em matéria de aprendizagem.

Em maio de 1939, o então chefe do govêrno, GETúlio $V_{A R-}$ GAS, determinava por decreto que as fábricas de mais de 500 operários mantivessem por sua conta escolas profissionais para os menores seus empregados.

Os estudos para regulamentação da obrigação acima conduziram o govêrno à conclusão de que aquela medida não satisfazia aos reclamos do processo de industrialização por que passava o País.

Parecia necessária uma regulação muito mais ampla do processo de aprendizagem, que tomou forma em decretos-leis que vamos apreciar a seguir.

\section{A APRENDIZAGEM NA LEGISLAÇÃO DO ENSINO INDUSTRIAL BRASILEIRO}

A influência de tão longa tradição histórica se fêz sentir de modo decisivo sôbre o ensino industrial brasileiro, sistematizado pelo Decreto-lei n 4.073, de 30 de janeiro de 1942 (Lei Orgânica do Ensino Industrial). Seis ordens de ensino são aí estabelecidas.

E' o que diz o artigo $6^{\circ}$ do citado decreto-lei.

Art. 6 $\mathrm{O}$ ensino industrial será ministrado em dois ciclos.

$\S 1$ \% primeiro ciclo do ensino industrial abrangerá as seguintes ordens de ensino:

13) Ensino industrial básico;

2a) Ensino de mestria;

3a) Ensino artesanal;

4a) Aprendizagem 
$\S 2{ }^{\circ}$ O segundo ciclo do ensino industrial compreenderá as seguintes ordens de ensino:

1:) Ensino técnico;

2a) Ensino pedagógico.

O Estado regula tôdas essas ordens de ensino. Custeia e administra os tipos preconizados em escolas profissionais oficiais federais, estaduais e municipais. Permite que pessoas físicas ou juridicas os mantenham desde que sigam os padrões fixados pelo decreto-lei acima citado, e se submetam à fiscalização do Estado.

$\mathrm{E}^{\prime}$ o que estabelece o artigo 60 do mesmo decreto-lei.

Art. 60. Além das escolas industriais e escolas técnicas federais, mantidas e administradas sob a responsabilidade da União, poderá haver duas outras modalidades dêsses estabelecimentos de ensino: os equiparados e os reconhecidos.

$\S 1 \%$ Equiparadas serão as escolas industriais ou escolas técnicas mantidas e administradas pelos Estados ou pelo Distrito Federal, e que hajam sido autorizadas pelo Govêrno Federal.

$\S 2^{\circ}$ Reconhecidas serão as escolas industriais ou escolas técnicas mantidas e administradas pelos municipios ou por pessoa natural ou pessoa juridica de direito privado, e que hajam sido autorizadas pelo Govêrno Federal.

$\S 3^{\circ}$ Conceder -se-á a equiparação ou o reconhecimento, mediante prévia verificação, ao estabelecimento de ensino cuja organização, sob todos os pontos-de-vista, possuir as imprescindiveis condições de eficiência.

$\S 4^{\circ}$ A equiparação ou reconhecimento será concedido com relação a um ou mais cursos de formação profissional determinados, podendo, mediante a neecssária verificação, estender-se a outros cursos também de formação profissional.

$\S 5^{\circ}$ A equiparação ou reconhecimento será suspenso ou cassado, para um ou mais cursos, sempre que o estabelecimento de ensino, por deficiência de organização ou quebra de regime, não assegurar a existência das condições de eficiência imprescindiveis .

$\S 6^{\circ}$ O Ministério da Educação exercerá inspeção sôbre as escolas industriais e escolas técnicas equiparadas e reconhecidas, e lhes dará orientação pedagógica.

$\S 77^{\circ}$ Escolas industriais ou escolas técnicas federais, não incluídas na administração do Ministério da Educação, dêste receberão orientação pedagógica.

Nos têrmos da Lei Orgânica citada, dois tipos de pessoas poderão manter ensino industrial: as de direito público (União, Estados, municipios) e as de direito privado (pessoas juridicas e pessoas fisicas). 
Há, entretanto, um ramo de ensino industrial que a lei impõe seja compulsòriamente ministrado, custeado e dirigido pelas pessoas jurídicas de direito privado, que são as emprêsas industriais, embora regulado e fiscalizado pelo Estado. E' o ensino de aprendizagem. E' o que estabelece o artigo 67 do citado decreto-lei $n^{\circ} 4.073$, de 30 de janeiro de 1942 .

Art. 67. O ensino industrial das escolas de aprendizagem será organizado e funcionará, em todo o Pais, com observância das seguintes prescrições:

I - O ensino dos ofícios, cuja execução exija formação profissional, constitui obrigação dos empregadores para com os aprendizes, seus empregados.

II - Os empregadores deverão, permanentemente, manter aprendizes, a seu serviço, em atividades cujo exercício exija formação profissional.

III - As escolas de aprendizagem serão administradas, cada qual separadamente pelos próprios estabelecimentos industriais a que pertençam, ou por serviços, de âmbito local, regional ou nacional, a que se subordinam as escolas de aprendizagem de mais de um estabelecimento industrial.

IV - As escolas de aprendizagem serão localizadas nos estabelecimentos industriais a cujos aprendizes se destinem, ou na sua proximidade.

$\mathrm{V}$ - O ensino será dado dentro do horário normal de trabalho dos aprendizes, sem prejuizo de salário para êstes.

VI - Os cursos de aprendizagem terão a duração de um, dois, três ou quatro anos.

VII - Os cursos de aprendizagem abrangerão disciplinas de cultura geral e de cultural técnica, e ainda as práticas educativas. que fôr possivel, em cada caso, ministrar.

VIII - Preparação primária suficiente e aptidão física e mental necessária ao estudo do ofício escolhido são condições exigiveis do aprendiz para matrícula nas escolas de aprendizagem.

IX - A habilidade dependerá de freqüência às aulas e de notas suficientes nos exercícios e exames escolares.

$\mathrm{X}$ - A conclusão de um curso de aprendizagem dará direito ao respectivo certificado de habilitação.

$\mathrm{XI}$ - Os professôres estarão sujeitos a prévia inscrição, mediante prova de capacidade, no registro competente do Ministério. da Educação.

XII - As escolas de aprendizagem darão cursos extraordinários para trabalhadores que não estejam recebendo aprendi- 
zagem. Êsses cursos, conquanto não incluídos nas secções formadas pelos cursos de aprendizagem, versarão sôbre os seus as suntos.

A indústria é composta de milhares de emprêsas grandes, médias e pequenas, sobretudo destas últimas. Por isso e para tornar possivel a aprendizagem prevista pelo Lei Orgânica do Ensino Industrial, uma nova Lei foi baixada, a de $n^{\circ} 4.048$, de 22 de janeiro de 1942, regulando e assegurando às fábricas a maneira e os recursos para realizarem o dever de ministrar aprendizagem.

\section{DECRETO-LEI N: 4.048, DE 22 DE JANEIRO DE 1942}

Art. 1\% Fica criado o Serviço Nacional de Aprendizagem dos Industriários.

Art. 2\% Compete ao Serviço Nacional de Aprendizagem dos Industriários organizar e administrar, em todo o Pais, escolas de aprendizagem para industriários.

Parágrafo único. Deverão as escolas de aprendizagem ministrar ensino de continuação e de aperfeiçoamento e especialização para trabalhadores industriários não sujeitos à aprendizagem.

Art. 3 O Serviço Nacional de Aprendizagem dos Industriários será organizado e dirigido pela Confederação Nacional da Indústria .

Art. 4. Serão os estabelecimentos industriais das modalidades de indústria enquadrados na Confederação Nacional da Indústria obrigados ao pagamento de uma contribuição mensal para montagem e custeio das escolas de aprendizagem.

O sistema adotado pelá legislação decretada em 1942 veio a ser alçado em dever constitucional dos empregadores quando, em 1946, a nossa Lei Magna fixou, no inciso IV do artigo 168:

"as emprêsas industriais e comerciais são obrigadas a ministrar, em cooperação, aprendizagem aos seus trabalhadores menores, pela forma que a lei estabelecer, respeitados os direitos dos professôres". 